\title{
Predicting the Pressure Drops across Cellulose Acetate Filters *
}

\author{
by $R$. W. Dwyer \\ Philip Morris Research Center, Richmond, Virginia, U.S.A.
}

\section{SUMMARY}

A theoretical model of the pressure drop across a fibrous cigarette filter is derived. The pressure drop is expressed as a function of the filter dimensions, the fiber tow characteristics, the filter weight, the fluid flow rate, and a filter fiber factor. The fiber factor is affected by the distribution of the fibers within the filter, the relative orientations of the fibers, and their cross-sectional shapes. The model allows one to accurately calculate the influences of these variables on the filter pressure drop. Additionally, it can be used to predict capability curves and select an optimum cellulose acetate tow for a given filter pressure drop.

\section{ZUSAMMENFASSUNG}

Zur Berechnung des Zugwiderstandes in einem aus Fasern bestehenden Zigarettenfilter wird ein theoretisches Modell abgeleitet. Der Druckabfall wird in Abhängigkeit von der Größe des Filters, von den Eigenschaften des Faserkabels, dem Gewicht des Filters, der Durchflußgeschwindigkeit und von einem Faser-Faktor dargestellt. Der Faser-Faktor wird bestimmt von der Verteilung der Fasern im Filterkabel, von der Orientierung der Fasern im Verhältnis zum Rauchstrom und von deren Querschnittsform. Mit Hilfe des Modells kann genau berechnet werden, in welchem Maße der Zugwiderstand eines Filters durch die einzelnen Variablen beeinflußt wird. Darüber hinaus läßt sich mit ihm die Wirksamkeit eines Filters an Hand von Kurven im voraus bestimmen und ein für einen bestimmten Zugwiderstand optimales Celluloseacetatkabel wählen.

\footnotetext{
* Received: Sth July 1984 - accepted: 26th November 1985.
}

\section{RESUME}

On utilise un modele théorique pour le calcul de la résistance au tirage dans un bout-filtre en mèche d'acétate. La résistance au tirage est exprimée en fonction de la dimension du bout-filtre, des propriétés de la mèche, du poids du filtre, du débit gazeux et d'un facteur caractérisant les fibres. Ce dernier dépend de la répartition des fibres dans le filtre, de leur orientation par rapport au courant de fumée ainsi que de leur section transversale. Au moyen de cette formule, on peut calculer exactement l'influence respective des différentes variables sur la résistance au tirage d'un bout-filtre. De plus, elle permet aussi de déterminer à l'avance les courbes d'efficacité d'un bout-filtre ainsi que de choisir la mèche d'acétate de cellulose optimale correspondant à une résistance au tirage donnée.

\section{INTRODUCTION}

The selection of an appropriate cellulose acetate tow for fabricating cigarette filters is prescribed by the pressure drop and efficiency properties required for a product. However, since filtration efficiency and pressure drop are strongly coupled parameters (1), tow selection is primarily a matter of determining the optimum item for a required pressure drop. This choice can be made by comparing the capability curves of a variety of tows and selecting the one with the greatest manufacturing and economic benefits. Capability curves show the range of weights and corresponding pressure drops of filters made from specific tow items. The objective of this study is to provide a model for predicting such curves thereby facilitating the selection of the optimum cellulose acetate tow. 


\section{THE PRESSURE DROP EQUATION}

The pressure drop across a filter is dependent on the geometry and structure of the filter and the flow field of the fluid passing through it. There are a number of well documented filter pressure-drop equations in the literature $(2-5)$. Of these, the LANGMUIR equation (2) proved most suitable for this study. This equation was derived on the assumption that the filter is composed of cylindrical fibers oriented parallel to the direction of fluid flow. Furthermore, LANGMUIR assumed the flow to be laminar and the fibers uniformly distributed throughout the filter. Because of its importance to this work and the relative obscurity of the original publication, a derivation of the LANGMUIR equation is included in the Apperidix. The equation may be written:

$$
\Delta \mathrm{P}=\frac{4 \pi \mu \mathrm{B} \mathrm{L} \mathrm{L}_{\mathrm{f}} \mathrm{Q} \alpha \Phi}{\mathrm{A}_{\mathrm{f}} \mathrm{A}_{\mathrm{F}}},
$$

where (in the centimeter-gram-second (C.G.S.) system):

$\Delta \mathrm{P}$ is the filter pressure drop $\left(\mathrm{dyn} / \mathrm{cm}^{2}\right)$,

$\mu \quad$ is the fluid viscosity $(\mathrm{g} /(\mathrm{cm} \cdot \mathrm{s}))$,

$Q$ is the fluid flow rate $\left(\mathrm{cm}^{3} / \mathrm{s}\right)$,

$L_{f}$ is the length of the filter fibers $(\mathrm{cm})$,

$\alpha$ is the fraction of the filter occupied by solids,

$A_{F}$ is the face area of the filter $\left(\mathrm{cm}^{2}\right)$,

$A_{f}$ is the cross-sectional area of a filter fiber $\left(\mathrm{cm}^{2}\right)$,

$B$ is a factor related to the shape, orientation, and distribution of the filter fibers.

The term $\Phi$ is called the hydrodynamic factor, and is a function of the filter's occupied volume, $\alpha$ :

$$
\Phi=\left(-\ln \alpha+2 \alpha-\frac{\alpha^{2}}{2}-\frac{3}{2}\right)^{-1} \text {. }
$$

This relationship can be simplified over the range of $\alpha$ encountered in cigarette filters. Figure 1 shows that for $0.07 \leq \alpha \leq 0.20$ (which corresponds to filter porosities between 0.80 and 0.93 ), the relationship between $\Phi$ and $\alpha$ may be written:

$$
\Phi=10.0 \alpha .
$$

This approximation introduces less than a three percent deviation from equation 2 in this range.

The LANGMUIR equation may be transformed into one containing more familiar terms through the following relationships:

$$
\begin{aligned}
& \alpha=m /\left(\varrho A_{p} L_{p}\right), \\
& L_{f}=m L_{d} / D, \\
& A_{f}=d /\left(\varrho L_{d}\right),
\end{aligned}
$$

Figure 1.

The hydrodynamic factor $(\Phi)$ as a function of the filter fraction occupled by solids (a) [curved line]; the straight line is the approximation $\Phi=10.0 \alpha$ (equation 3).

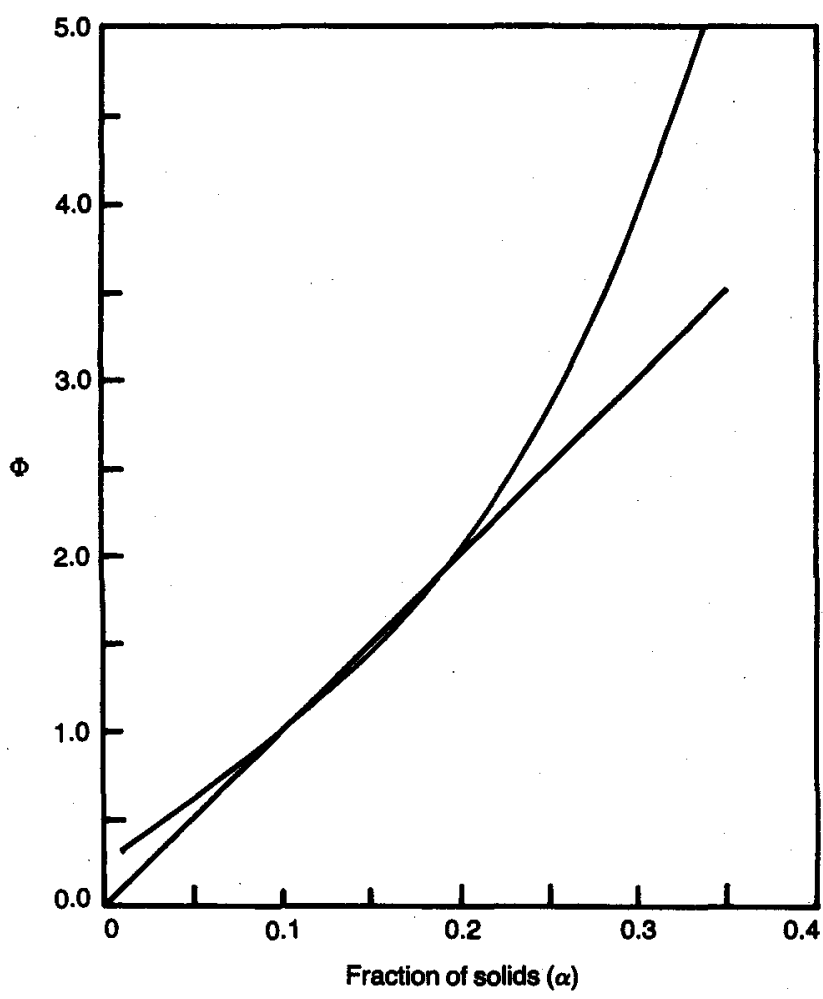

where (in the C.G.S. system):

$m$ is the mass of tow in the filter (g),

Q is the density of the tow $\left(\mathrm{g} / \mathrm{cm}^{3}\right)$,

$\mathrm{L}_{\mathrm{F}}$ is the filter length $(\mathrm{cm})$,

D is the denier of the tow $(\mathrm{g} / 900,000 \mathrm{~cm})$,

d is the denier of the individual fibers $(\mathrm{g} / 900,000 \mathrm{~cm})$,

$\mathrm{L}_{d}$ is the characteristic length with which denier is defined $(900,000 \mathrm{~cm})$.

Using equations 3 through 6, the pressure-drop expression may be rewritten as:

$$
\Delta \mathrm{P}=\frac{40 \pi \mu \mathrm{L}_{\mathrm{d}}^{2} \mathrm{~B} \mathrm{Q} \mathrm{m^{3 }}}{\varrho \mathrm{A}_{\mathrm{F}}^{3} \mathrm{~L}_{\mathrm{F}}^{2} \mathrm{~d} \mathrm{D}}
$$

or, in terms of filter circumference, $\mathrm{C}_{\mathrm{F}}$, as:

$$
\Delta \mathrm{P}=\frac{2560 \pi^{4} \mu \mathrm{L}_{\mathrm{d}}^{2} \mathrm{~B} \mathrm{Q} \mathrm{m^{3 }}}{\varrho \mathrm{C}_{\mathrm{F}}^{6} \mathrm{~L}_{\mathrm{F}}^{2} \mathrm{~d} \mathrm{D}}
$$

KEITH (6) and RASMUSSEN (7) have developed pressuredrop models for cellulose acetate filters which are similar to each other, but substantially different from equation 8. Their models are based on linear combinations 
Figure 2.

The dependence of filter pressure drop $(\triangle P)$ on the fluld flow rate (Q). The filter tow designations are $d /\left(D \cdot 10^{-3}\right)$; the filter dimensions are $L_{F}=2.50 \mathrm{~cm}$ and $C_{F}=2.43 \mathrm{~cm}$.

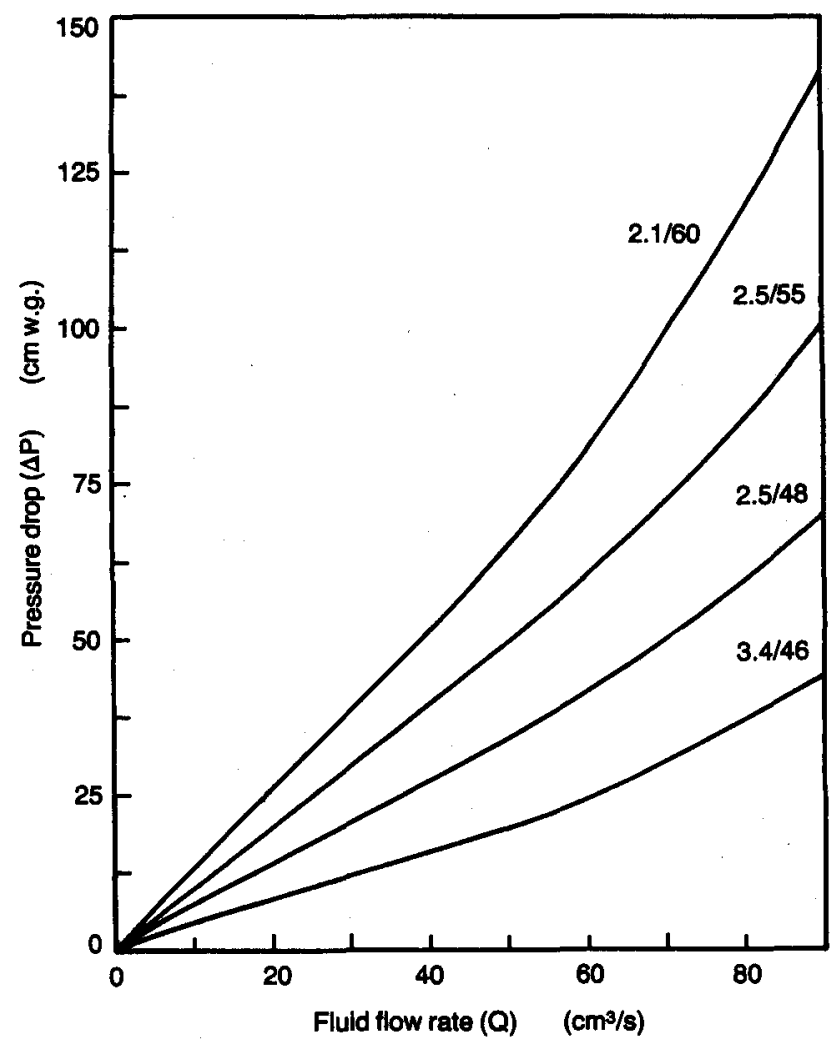

of perpendicular and parallel flow fields. Their treatments require a knowledge of an agglomeration factor" which accounts for non-uniformity in the distribution of the fibers throughout the filter.

Equation 8 relates the pressure drop of a fibrous filter to its dimensions $\left(C_{F}, L_{F}\right)$, the tow characteristics ( $Q, d$, $D)$, the tow mass (m), the fluid flow rate $(Q)$, and the filter fiber factor, $B$. Therefore, if we know $B$, the pressure drop of any tow item can be calculated as a function of flow rate and mass for a given set of filter dimensions. In theory, the $B$ term is a function of the fiber orientation, the fiber distribution, and the crosssectional shape of the fibers. This term should be independent of the other terms in equation 8 with the exception of $\mathrm{m}$. We anticipate a dependence on $\mathrm{m}$ because if the tow mass is varied in a filter of fixed dimensions, the relative fiber orientations will be altered. The validity of the form of equation 8 (or equation 7) can be tested at this point for cases in which $B$ is a constant.

The pressure-drop equation predicts a linear relationship between $\Delta \mathrm{P}$ and the fluid flow rate when all of the other variables are held fixed. Figure 2 illustrates such behavior for a variety of cellulose acetate filters. Thus, this linear dependence is demonstrated for flow rates below $50 \mathrm{~cm}^{3} / \mathrm{s}$.

\footnotetext{
" In all cases where pressure-drop values are reported, the filter samples were encased in a sheath which prevented air flow through the wrapper.
}

In order to examine the effect of filter length on pressure drop, the density of the filter rod, $Q_{F}$, must be considered. Equation 7 predicts $\Delta \mathrm{P}$ to vary linearly with $\mathrm{m}^{3} /\left(\mathrm{L}_{\mathrm{F}}^{2} \mathrm{~A}_{\mathrm{F}}^{3}\right)$. This factor is equal to $\mathrm{Q}_{\mathrm{F}}^{3} \mathrm{~L}_{\mathrm{F}}$. Therefore, the pressure drop should vary linearly with filter length, as is commonly observed.

The pressure-drop equation shows $\Delta \mathrm{P}$ to be inversely proportional to the filter tow circumference raised to the sixth power. $C_{F}$ is the filter circumference corrected for the thickness of the filter wrapper. We have found, in examining the effects of plug wrap thickness on filter performance, that graphs of $\log \Delta P$ vs. $\log C_{F}$ yield a straight line with a slope of -6 . Others (8) report a value of -5.6 for this exponent.

Finally, equation 8 predicts that, at a constant mass, the filter pressure drop is inversely proportional to the fiber denier and the total denier. The only data of this nature at our disposal are for two tow items: a 2.5/ $48,000 / \mathrm{Y}$ tow and a $3.3 / 44,000 / \mathrm{Y}$ tow. Filters with a $10.0 \mathrm{~cm}$ length and a $2.47 \mathrm{~cm}$ circumference were fabricated at a mass of $0.675 \mathrm{~g}$. The ratio of the pressure drops of these filters was found to be 1.18 while the inverse ratio of their products $D \cdot d$ is 1.21 . The small discrepancy can probably be ascribed to differences in the $B$ values for the filters (cf. Figure 3).

At this point, the role of the filter fiber factor B needs to be determined. LANGMUIR, in his original report, showed that $B$ is affected by the distribution of the fibers within the filter, the relative orientations of the fibers, and their cross-sectional shapes. These effects are addressed in the following sections.

\section{a. The Fiber Distribution}

A major problem in formulating a theoretically based model of filter pressure drop lies in expressing the effects of the fiber distribution. Consider this in light of equation 8. If a conventional tow filter is altered by forming a continuous channel through it along its major axis, the filter pressure drop is reduced. However, all of the factors on the right-hand side of equation 8 are unchanged by this alteration except $B$.

Another illustration of the influence of the fiber distribution is shown in Figure 3. These capability curves display experimental measurements of $\Delta \mathrm{P}$, at a flow rate of $17.5 \mathrm{~cm}^{3} / \mathrm{s}$, as a function of tow mass. The filters were constructed using the Hauni AF-1/KDF-2 process at a filter-making velocity of $67 \mathrm{~cm} / \mathrm{s}$. The filters were made at different tow contents and at a variety of bloom or tow-bulking conditions. Obviously, at a given filter mass, the pressure drop can vary significantly. This variation is reflected in the fiber factor which achieves its maximum value at a given mass when the fibers are most uniformly distributed throughout the filter. Thus $B$ is a function of filter tow bloom. The optimum region for producing filters is where the ratio of $\Delta \mathrm{P}$ to $\mathrm{m}$ is the greatest.

In formulating the pressure-drop model, we make the assumption that the fiber distributions are near opti- 
Figure 3.

Experimental capablilty results for filters fabricated from two different tow thems. Notice the range of pressure drop $(\Delta P)$ for a given mass $(\mathrm{m})$. The filter dimensions are $L_{F}-10.0 \mathrm{~cm}$ and $C_{F}=2.43 \mathrm{~cm}$. The solld lines are from equations 10 and 11 . The masses are those of the tow only, l.e. without plasticizer or plug wrap.

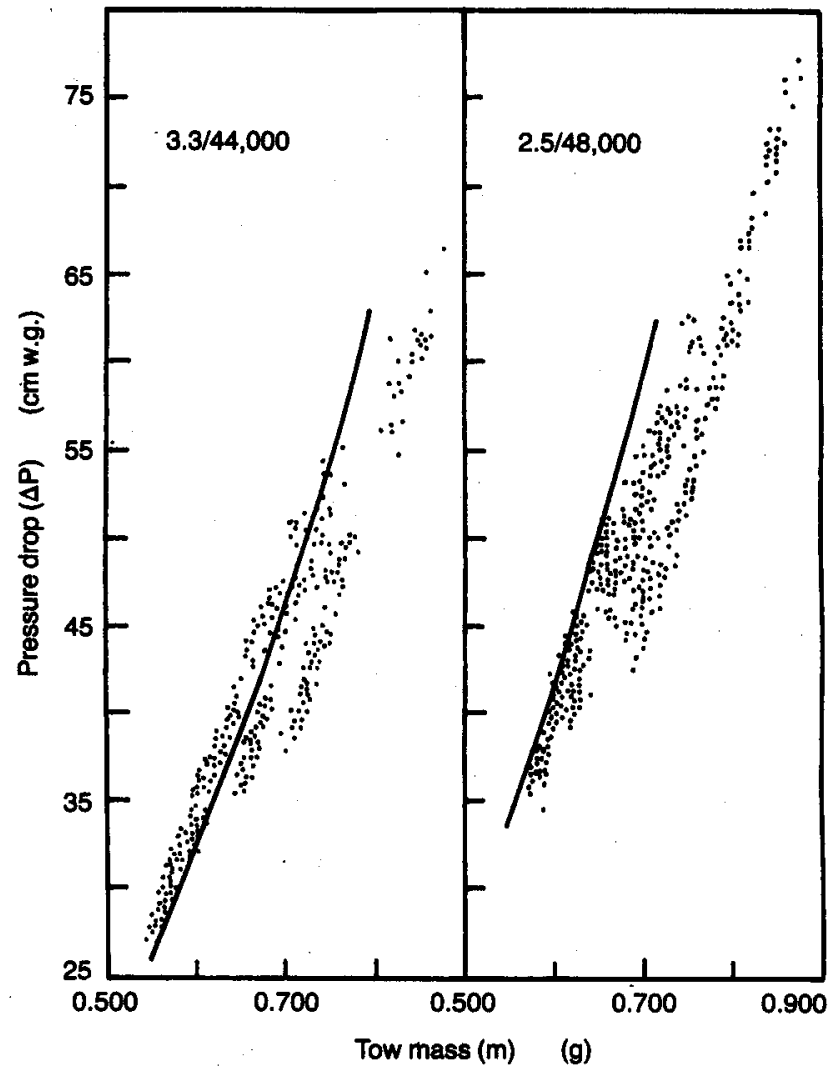

mum, i.e. the value of $B$ for any filter is close to its maximum. The assignment of an optimum value is based on analyzing many sets of experimental data. Keep in mind, however, that discrepancies between theoretical predictions and experimental measurements may arise when the bloom is less than optimum. The method of determining the best value of $B$ is described in the following section.

\section{b. The Orientation of Filter Fibers}

There is a considerable variation in the length of tow band which can be incorporated into a filter of fixed dimensions. This characteristic is reflected in a tow's capability range. At the low end of this range, the length of tow band is about $10 \%$ greater than the filter length. At the high end, the tow length can exceed the filter length by as much as $100 \%$ (9). Due to this variation, it is anticipated that the relative contribution of perpendicular fiber orientations will increase as $\mathrm{L}_{\mathrm{f}}$ increases. Therefore, $B$ is expected to be a function of the amount of tow in a given filter.

To test this hypothesis, we examined capability data for forty different tow items. These data were made available to us by the Filter Products Research Laboratory of the Eastman Kodak Company. They evaluated the minimum, maximum, and midrange pressure drops (at $Q=17.5 \mathrm{~cm}^{3} / \mathrm{s}$ ) and unplasticized tow weights of filters $12.0 \mathrm{~cm}$ in length and $2.47 \mathrm{~cm}$ in circumference (the actual tow circumference, corrected for plug wrap thickness, was $2.44 \mathrm{~cm}$ ). The fiber deniers ranged from 2.1 to 5.0 and the tow deniers ranged from 31,000 to 60,000 . All of the tows were Y-shaped in cross section. The filters were manufactured at $67 \mathrm{~cm} / \mathrm{s}$ with the Hauni AF-1/KDF-2 process with a transport jet. Replicate capability determinations were performed on as many as 146 different bales of a given tow item.

The values of $B$ and $L_{f}$ were calculated for each data set using equations 8 and 5, respectively. Graphs of B vs. $\mathrm{L}_{\mathrm{F}} / \mathrm{L}_{\mathrm{f}}$ demonstrated a linear tendency for each tow item. The linear coefficients varied from sample to sample, but showed no obvious correlations with fiber denier or total denier. Weighted averaging of the linear coefficients from each tow's data set resulted in the relationship:

$$
B=0.315+0.765 \mathrm{~L}_{\mathrm{F}} / \mathrm{L}_{f} .
$$

The weighting was predicated on the number of replications for each tow.

It is interesting to note that in the limit of $L_{f}$ equal to $L_{F}$, the value of $B$ is 1.08 . LANGMUIR showed that $B$ should equal 1.00 in this limit for well distributed cylindrical fibers (2).

Substituting equation 5 into equation 9 gives:

$$
B=0.315+0.765 \frac{L_{F} D}{m L_{d}} .
$$

Using equations 8 and 10, the minimum, midpoint, and maximum pressure drops were calculated from the corresponding Filter Products Research Laboratory tow mass data. It was observed that the calculated pressure drops of the small-fiber filters were slightly higher than the experimental values. Conversely, for the higher fiber deniers, the calculated values were somewhat lower. Maximum correspondence between prediction and experiment was obtained by correcting the B factors with a multiplier:

$$
B=\left(0.315+0.765 \frac{L_{k} D}{m L_{d}}\right)\left(0.560+0.241 d^{j}\right) \text {. }
$$

This equation shows that the fiber orientation is a function of both its length in the filter (equation 9) and its cross-sectional width, i.e. the fiber diameter is proportional to the square root of its denier (equation 6). The three-point pressure drops for the filters described in the Filter Products Research Laboratory data set were calculated using equations 8,10 and 11 . The average of the differences between computed and measured 
Figure 4.

Experimental and predicted capablilty data for 3.3/44,000 tow. The experimental points reflect the $\pm \sigma$ ranges, where $\sigma$ is the standard deviation (from Table 1).

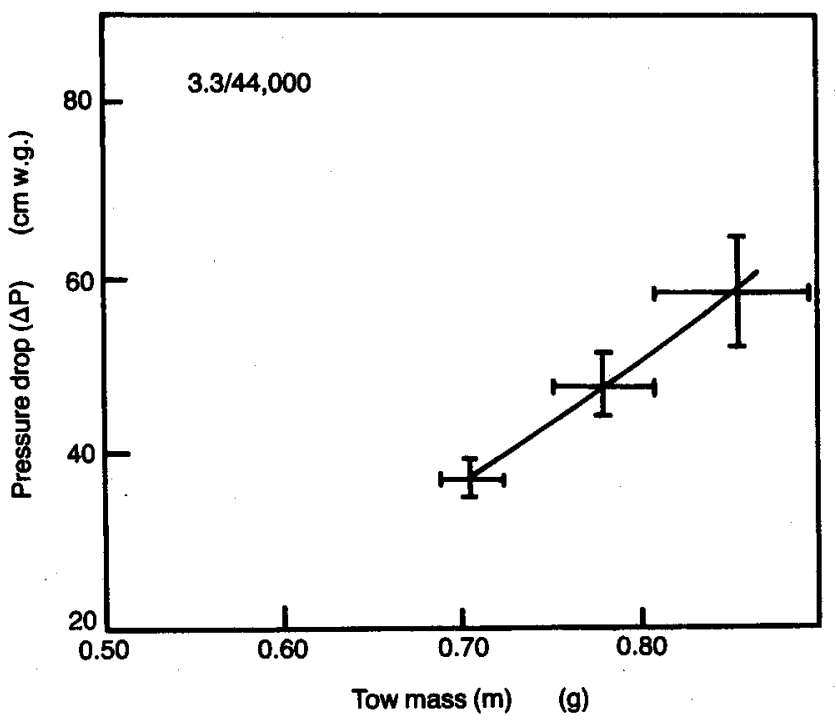

values was found to be less than the average experimental standard deviation reported for the pressuredrop data. Figures 4, 5 and 6 illustrate the agreement of the predictions with experiment.

At this point we would like to emphasize that we believe equations 7 and 8 to be perfectly general for fibrous filters. The only empiricism is introduced in attempting to resolve B into its component effects, as in equations 9 and 11. It would not be surprising to find that these latter equations are sensitive to the type of processing performed to bloom the tow and fabricate the filters. However, within the confines of a particular process, i.e. Hauni AF-1/KDF-2, we have found equations 10 and 11 to be excellent predictors. As stated earlier, it is difficult and probably not very useful to quantify the relationship between $B$ and bloom. Instead, we have chosen the coefficients in equations 9 and 11 to reflect the averages found in what are considered to be well bloomed tows.

Also, we have not considered any fiber shapes other than the $Y$ cross section. The analysis of a limited number of filters made with $X$ and I-shaped fiber cross sections suggests that they behave substantially the same as the $\mathrm{Y}$ fibers. This means that equations 10 and 11 should be adequate for such fibers. However, fibers with circular cross sections have the same functional form but different coefficients for these equations. Unfortunately, we have insufficient data to quantify a relationship with filters composed of circular cross-section fibers.

A final aspect of calculating capability curves involves selecting their minimum and maximum points. From analysis of the Filter Products Research Laboratory data, we found the minimum and maximum amounts of tow in a particular filter volume to be linearly related to the total denier of the tow. Figure 7 illustrates this
Figure 5.

Experimental and predicted capability data for tow Items.

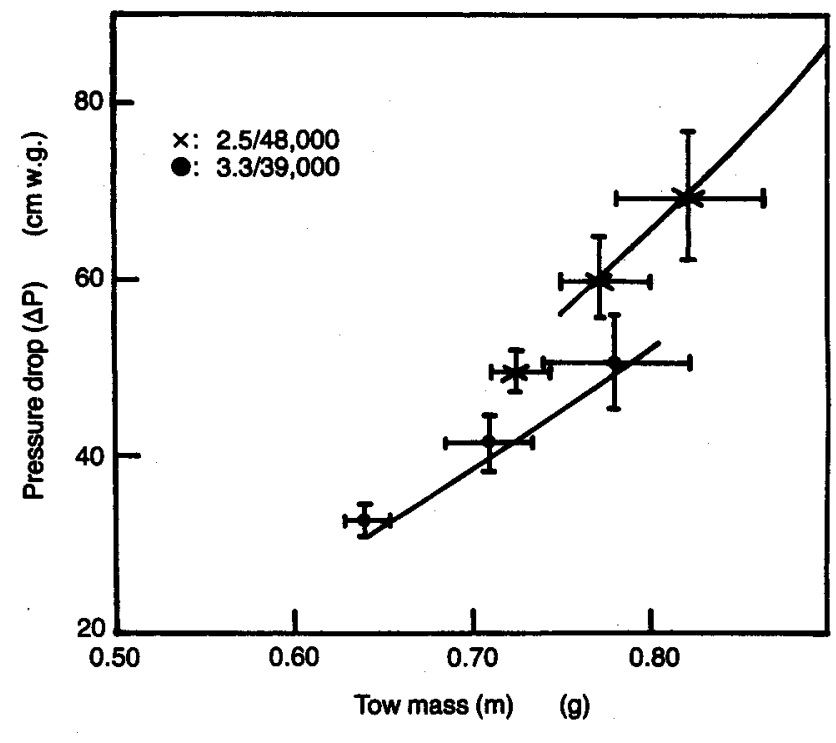

Figure 6.

Experimental and predicted capability data for three tow Htems.

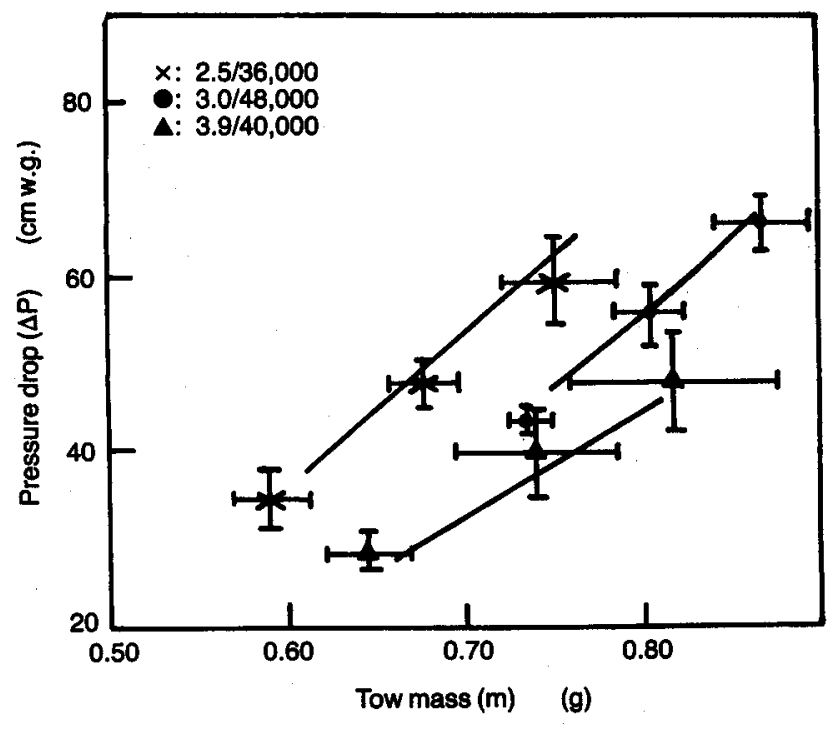

relationship. This analysis was performed by calculating the fraction of the filter occupied by solids (equation 4) for the minimum points of each of the forty tow items. The linear equation relating this parameter to tow denier is:

$$
\alpha_{\min }=0.0250+\frac{D}{6.41 \cdot 10^{5}}
$$

This best-fit line is included in the figure. A similar analysis was performed for the maximum points with the result:

$$
\alpha_{\max }=0.0450+\frac{D}{6.41 \cdot 10^{5}}
$$




\section{Figure 7.}

The relationship between the fraction of solids $(\alpha)$ and the tow deniers (D). of forty tow hems. The experimental points represent the minimum amounts $\left(\alpha_{\min }\right)$ and maximum amounts $\left(\alpha_{\max }\right)$ of tow which could be incorporated into filters of $12.0 \mathrm{~cm}$ lengths and $2.44 \mathrm{~cm}$ inside circumferences.

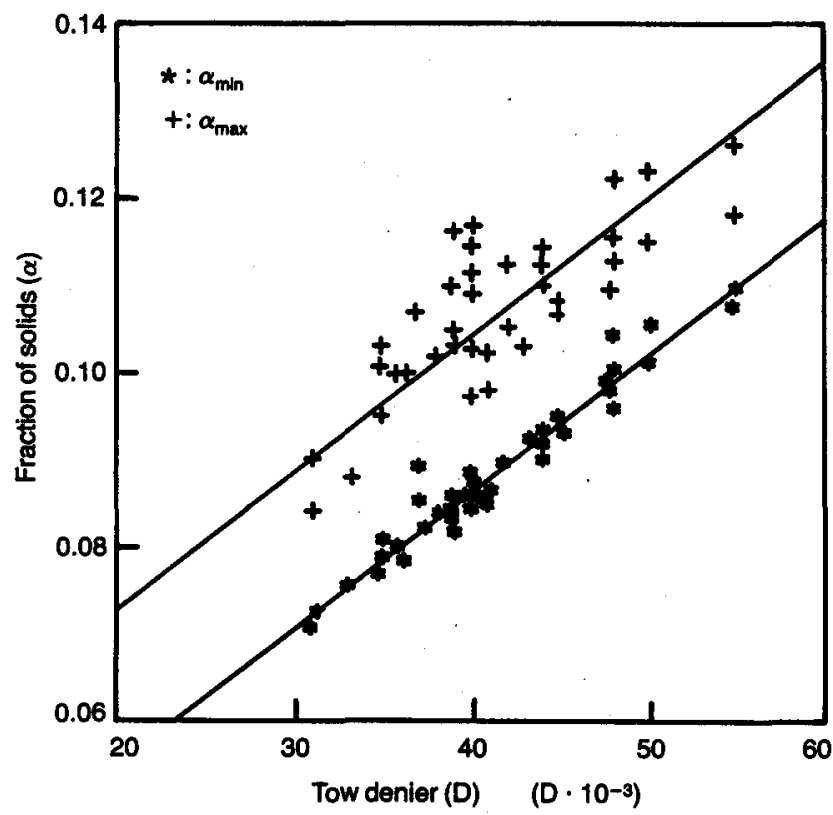

The $\alpha_{\max }$ values do not demonstrate the same degree of linearity as $\alpha_{\text {min }}$. We attribute this to the subjective nature of determining the end point. The coefficients in equation 13 were found by forcing the slope to agree with that in equation 11, and calculating the best-fit intercept. The predicted lines in Figures 4 through 6 were found using equations 12 and 13 to determine the limiting values of $\alpha$. The $\alpha_{\min }$ and $\alpha_{\max }$ values were substituted into equation 4 to find $m_{\min }$ and $m_{\max }$.

\section{SELECTING FILTER TOWS}

In this section several applications of the filter pressure-drop model are illustrated. The first example demonstrates the construction of capability curves. The second develops a scheme for generating a list of potential tow items for achieving a target filter pressure drop. Also included is a discussion of range-extension effects on tow selection based on a recently introduced tow processing modification.

Consider the determination of the capability curve for a $3.0 / 50,000 / \mathrm{Y}$ tow in a $10.0 \mathrm{~cm}$ filter with a finished circumference of $2.47 \mathrm{~cm}$. The tow circumference is obtained by correcting the finished circumference for the filter-wrap thickness:

$$
C_{F}=C_{F}^{\prime}-2 \pi t,
$$

where $C_{F}^{\prime}$ is the finished filter circumference and $t$ is the wrapper thickness. Allowing $t$ to equal $4.1 \cdot 10^{-3} \mathrm{~cm}$ for this example gives a $C_{F}$ value of $2.44 \mathrm{~cm}$.

Equations 12 and 13 yield 0.103 and 0.123 for $\alpha_{\min }$ and $\alpha_{\max }$. These values correspond to capability mass limits of $0.644 \mathrm{~g}$ to $0.769 \mathrm{~g}$ (from equation 4 , using $\varrho=$ $1.32 \mathrm{~g} / \mathrm{cm}^{3}$ for cellulose acetate). We elect to describe the capability curve with five points. The additional tow masses are selected within the range of $m_{\min }$ to $m_{\max }$. The values of $B$ are computed from equation 11 . Lastly, equation 8 is used to calculate the pressure drops. For this particular example, equation 8 can be reduced to:

$$
\Delta P=1.55 \cdot 10^{5} \mathrm{~B} \mathrm{~m}^{3} \quad\left(\mathrm{dyn} / \mathrm{cm}^{2}\right),
$$

where the factors of equation 8 are: $Q=17.5 \mathrm{~cm}^{3} / \mathrm{s}$, $\mu=1.83 \cdot 10^{-4} \mathrm{~g} /(\mathrm{cm} \cdot \mathrm{s}), \mathrm{L}_{\mathrm{d}}=900,000 \mathrm{~cm}, \mathrm{Q}=1.32$ $\mathrm{g} / \mathrm{cm}^{3}, \mathrm{C}_{\mathrm{F}}=2.44 \mathrm{~cm}, \mathrm{~L}_{\mathrm{F}}=10.0 \mathrm{~cm}, \mathrm{~d}=3.00, \mathrm{D}=$ 50,000 . To convert the pressure drop from units of $\mathrm{dyn} / \mathrm{cm}^{2}$ to $\mathrm{cm}$ w.g., the conversion factor $1.02 \cdot 10^{-3}$ [cm w.g. $/\left(\right.$ dyn $\left.\left./ \mathrm{cm}^{2}\right)\right]$ is employed, i.e.

$$
\Delta \mathrm{P}=158 \mathrm{~B} \mathrm{~m}^{3} \quad \text { (cm w.g.) }
$$

The results are summarized in Table 1.

Another application of the pressure-drop model is the prediction of specific tow items which will achieve a target pressure drop. As an illustration, consider an example in which the $\Delta P$ target is $12.5 \mathrm{~cm}$ w.g. (for $Q-$ $17.5 \mathrm{~cm}^{3} / \mathrm{s}$ ) at a filter length of $2.50 \mathrm{~cm}$ and a $2.44 \mathrm{~cm}$ unwrapped tow circumference. At this point we make the decision to constrain the tow items to those which will achieve this pressure drop at the center of their capability range. Explicitly, this constraint is manifested in the expression chosen for the $\alpha$ factor. Comparison of equations 12 and 13 shows the midrange equation to be:

$$
\alpha_{\text {mid }}=0.0350+\frac{D}{6.41 \cdot 10^{5}}
$$

Table 1.

Factor $B$ and pressure drop ( $\Delta P$ ) values as a function of the tow mass (m).

\begin{tabular}{c|c|c}
\hline $\begin{array}{c}\text { Tow mass (m) } \\
(\mathrm{g})\end{array}$ & $\begin{array}{c}\text { B } \\
\text { (equation 11) }\end{array}$ & $\begin{array}{c}\text { Pressure drop }(\Delta \mathrm{P}) \\
\text { (equation 16) } \\
\text { (cm w.g.) }\end{array}$ \\
\hline 0.644 & 0.953 & 40.2 \\
0.675 & 0.924 & 44.9 \\
0.705 & 0.897 & 49.7 \\
0.735 & 0.873 & 54.7 \\
0.769 & 0.848 & 61.0 \\
\hline
\end{tabular}


The selection of the intercept for such an expression is an important consideration in terms of filter firmness. Filters constructed from a tow at the high end of its capability range will be firmer than those made at lower capability points. Therefore, for a particularly low mass selection it is judicious to choose an intercept value closer to that of equation 13. Range extension leads to larger intercepts than the 0.0450 value of equation 13 . This point will be addressed in a following section.

The procedure for generating a list of tow items which will have a pressure drop of $12.5 \mathrm{~cm}$ w.g. at mid-capability range is as follows. An initial filter mass is chosen and used to obtain $\alpha$ from equation 4. Alternatively, one might assume an initial $\alpha$ value and use it to obtain the requisite $m$ value from equation 4 . With the $\alpha$ value, equation 17 is solved for $D$. For this example, we choose $\mathrm{m}$ equal to $0.175 \mathrm{~g}$. This corresponds to an $\alpha$ of 0.112 . From equation 17 , it is found that $D$ is equal to 49,400 . Substituting $D$ and $m$ into equation 10 yields 0.914 for B. Since equations 8 and 11 are both functions of the fiber denier, $d$, we have chosen an iterative technique for evaluating this factor. Initially, we use equation 10 for $B$ and solve equation 8 for d. Equation 8 is solved using the target $\Delta \mathrm{P}$ value of $1.23 \cdot 10^{4} \mathrm{dyn} / \mathrm{cm}^{2}$ $(12.5 \mathrm{~cm}$ w.g.). This results in a fiber denier of 3.00 . At this point, equation 11 is evaluated (rather than equation 10) with $d$ equal to 3.00 . The new value of $B$ is used in equation 8 to determine a refined value of $d$. The refined $d$ is substituted into equation 11, and equations 8 and 11 are solved repeatedly until the current fiber denier satisfies both. In this example, $d$ converged to a value of 2.91 after three iterations. Thus the model predicts a 2.9/49,400/Y cellulose acetate tow will achieve a filter pressure drop of $12.5 \mathrm{~cm}$ w.g. at a tow mass of $0.175 \mathrm{~g}$. Additional candidates are found by varying $m$ and repeating this process. Table 2 was generated in this manner.

If this filter is to be produced at a mass of $0.145 \mathrm{~g}$, it is worthwhile to examine tow items which will achieve the target pressure drop higher in their capability ranges. An $\alpha$ value of 0.093 corresponds to a filter porosity of almost $91 \%$, therefore the filter might be in- sufficiently firm. The firmness could be enhanced by reformulating equation 17 with a larger intercept, for example:

$$
\alpha=0.0420+\frac{D}{6.41 \cdot 10^{5}} .
$$

Repeating the tow selection scheme with equation 18 rather than equation 17 yields the tow item $2.0 / 33,000 /$ $\mathrm{Y}$. Thus, in addition to a $1.9 / 37,000 / \mathrm{Y}$, a $2.0 / 33,000 / \mathrm{Y}$ tow is capable of achieving target $\Delta \mathrm{P}$ at a filter tow mass of $0.145 \mathrm{~g}$. It is predicted that the latter will be somewhat firmer.

\section{RANGE EXTENSION}

The Celanese Corporation has introduced modifications to the cigarette filter fabrication process which can lead to substantial increases in the capability ranges of cellulose acetate tows (9). The obvious effect of this on our filter pressure-drop scheme involves the assignment of the intercept in the $\alpha_{\max }$ expression. Equation 13 was found by evaluating the capability ranges of conventionally processed filters. We have also examined the capability ranges of filters made with the Celanese modifications. A 3.0/35,000/Y tow was fabricated into filters $10.0 \mathrm{~cm}$ in length and with circumferences of $2.46 \mathrm{~cm}(2.43 \mathrm{~cm}$ tow circumference). Additionally, a $2.0 / 30,000 / Y$ tow was used in $10.8 \mathrm{~cm}$ length filters with $2.47 \mathrm{~cm}$ circumferences $(2.44 \mathrm{~cm}$ tow circumference). Both sets of filters were manufactured at $67 \mathrm{~cm} / \mathrm{s}$ with the Hauni AF-1/KDF-2 process with a transport jet and the Celanese modifications. The experimental results and the calculated capability curves are illustrated in Figure 8. The solid portions of the curves were evaluated using equations 12 and 13 . The dashed portions were calculated by increasing the intercept of equation 13 from 0.0450 to 0.0550 . These results suggest that the pressure-drop model yields valid predictions in the extended portion of the capability ranges as well as in the conventional range.

Table 2.

The calculation of potentlal tow ltems.

\begin{tabular}{|c|c|c|c|c|c|}
\hline $\begin{array}{c}\text { Tow mass (m) } \\
\text { (g) }\end{array}$ & $\begin{array}{l}\text { Fraction } \\
\text { of solids }(\alpha) \\
\text { (equation } 4 \text { ) }\end{array}$ & $\begin{array}{l}\text { Tow denier (D) } \\
\text { (equation 17) }\end{array}$ & $\begin{array}{c}\text { B } \\
\text { (equation 10) }\end{array}$ & $\begin{array}{c}\text { Individual fiber } \\
\text { denier (d) } \\
\text { (equations } 8 \text { \& 11) }\end{array}$ & Potential tow item \\
\hline 0.130 & 0.083 & 31,000 & 0.821 & 1.50 & $1.5 / 31,000 / Y$ \\
\hline 0.145 & 0.093 & 37,100 & 0.859 & 1.90 & $1.9 / 37,000 / Y$ \\
\hline 0.160 & 0.103 & 43,300 & 0.890 & 2.36 & $2.4 / 43,000 / Y$ \\
\hline 0.175 & 0.112 & 49,400 & 0.914 & 2.91 & $2.9 / 49,000 / \mathrm{Y}$ \\
\hline 0.190 & 0.122 & 55,600 & 0.937 & 3.53 & $3.5 / 56,000 / Y$ \\
\hline
\end{tabular}


Figure 8.

Experimental and predlcted capablity data for two cellulose acetate tows. The solid curves represent the conventional capability range predictions and the dashed portions the extended range.

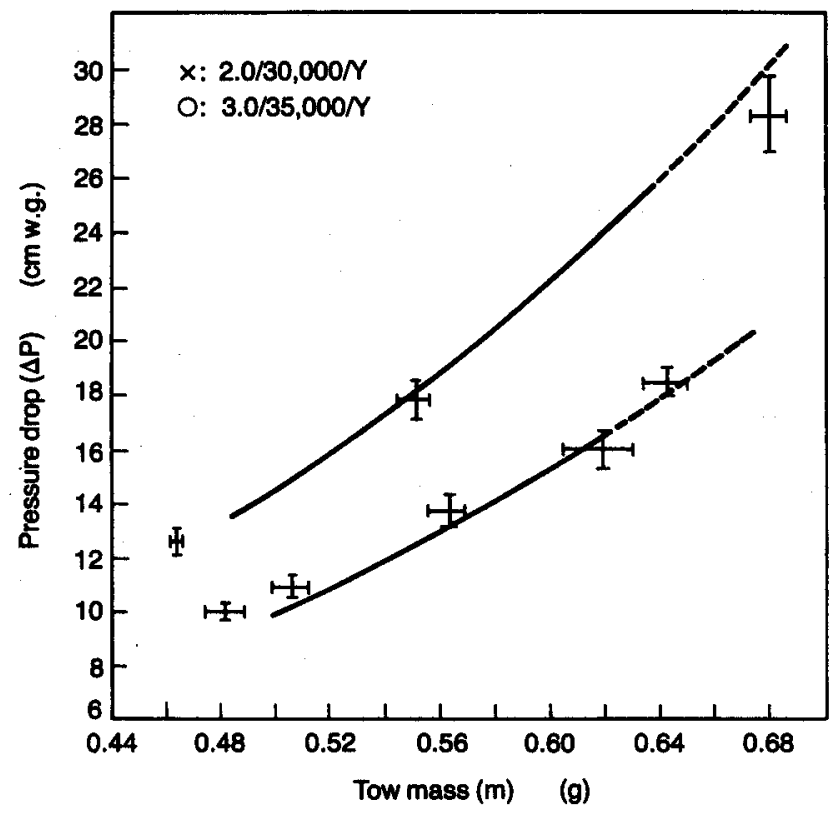

\section{CONCLUSIONS}

A model has been developed which relates the pressure drop of a fibrous filter to all of the physical and processing variables which are known to affect it. The form of this relationship is:

$$
\Delta P=\frac{2560 \pi^{4} \mu L_{d}^{2} B ~ Q m^{3}}{Q C_{F}^{6} L_{F}^{2} D d}
$$

The physical parameters influencing the filter pressure drop include its dimensions $\left(C_{F}, L_{F}\right)$, the filter fibers $(\varrho$, $D, d)$, and the fluid flowing through it $(\mu, Q)$. The processing variables are the mass of the fibers (m), and their spatial distribution and orientations (B).

Fibers made of materials other than cellulose acetate, or cellulose acetate fibers with an added plasticizer, may be considered by using the appropriate value of $\mathrm{Q}$. For all of the results reported in this paper, the filter masses are those of samples equilibrated at $60 \%$ relative humidity and $21^{\circ} \mathrm{C}$. These unplasticized samples contained about six percent water, but the effect of this on $\varrho$ may be considered negligible.

The influences of fluids other than air can be accounted for through $\mu$. The effect of the fluid temperature can be evaluated from the temperature dependence of the viscosity $(\mu \sim \sqrt{\mathrm{T}})$.

The third-order mass dependence of the filter pressure drop is reflected in the curvature observed in the upper regions of capability graphs. This increased slope is re- sponsible for the increased pressure-drop variability commonly observed in the higher ranges.

The reciprocal sixth power relationship between pressure drop and filter circumference illustrates the importance of careful circumference control. Relatively small variations in circumference can result in significant changes in pressure drop.

The value of the filter fiber factor, $B$, is a function of the fiber shape, the fiber distribution throughout the filter, and the fiber orientations. We considered only fibers with Y-shaped cross sections, and we assumed their perimeters to be equal to the circumference of a cylinder with an equivalent face area (see Appendix). This approximation should introduce no error as long as the fiber perimeter is proportional to the square root of its area, $A_{f}$. For example, the perimeter of a $\mathrm{Y}$-shaped cellulose acetate fiber is better approximated as $1.6 \sqrt{4 \pi A_{f}}$ than $\sqrt{4 \pi A_{f}}$. However, this scaling factor of 1.6 is implicitly included in the fiber parameter $B$ as we have developed it.

A major advantage of being able to predict filter pressure drops is the selection of the optimum filter material. In making such a selection, one must balance materials cost with processability and product quality. The ability to generate a list of items which will achieve a pressure-drop target should greatly facilitate this selection.

\section{REFERENCES}

1. Dwyer, R. W., S. G. Abel and M. L. Fleming: The effects of ventilation and pressure drop on filtration efficiency; presented at the 35th Tobacco Chemists' Research Conference, Winston-Salem, North Carolina, 1981.

2. Rodebush, W. H., I. Langmuir, V. K. LaMer: Filtration of aerosols and the development of filter materials; Office Sci. Res. Dev. (OSRD) 865, Office of the Publication Board, Department of Commerce, Washington, D.C., 1942, pp. 35-43.

3. Kuwabara, S.: The forces experienced by randomly distributed parallel circular cylinders or spheres in a viscous flow at small Reynolds numbers; J. Phys. Soc. Jpn. 14 (1959) 527-532.

4. Happel, J.: Viscous flow relative to arrays of cylinders; Am. Inst. Chem. Eng. J. 5 (1959) 174-177.

5. Kirsh, A. A., N. A. Fuchs: Studies on fibrous aerosol filters, II. Pressure drops in systems of parallel cylinders; Ann. Occup. Hyg. 10 (1967) 23-29.

6. Keith, C. H.: Experimental and theoretical aspects of cigarette smoke filtration; in: Removal of trace contaminants from the air, edited by V. R. Deitz, American Chemical Society, Washington, D.C., 1975, pp. 79-90.

7. Rasmussen, G. T.: Pressure drop generation in cigarette filters; presented at the conesta 1982 Symposium, Winston-Salem, North Carolina, U.S.A., CORESTA Information Bulletin 1982, special issue, p. 29. 
8. Bloom, H. T.: The effect of plugwrap thickness on filter pressure drop; Amcel-Europe International Seminar, Brussels, Belgium, May 1980.

9. Hyde, R. A.: An effective mechanical means for increasing the commercially usable range of cellulose acetate tow; presented at the 37th Tobacco Chemists' Research Conference, Crystal City, Washington, D.C., 1983.
10. Bird, R. B., W. E. Stewart and E. N. Lightfoot: Transport phenomena; John Wiley \& Sons, N.Y., 1960, pp. 51-54.

\section{Autbor's address:}

Philip Morris Research Center, P.O. Box 26583,

Richmond, Virginia, 23261, U.S.A.

\section{Appendlx}

DERIVATION OF THE LANGMUIR EQUATION $(2,10)$

\section{The Filter Model}

The model of the filter bed used in this derivation consists of a series of cylindrical fibers uniformly distributed throughout the bed and oriented parallel to the direction of fluid flow. The fluid flow is considered in a cylindrical volume element around each flber. The radius of this volume element is taken to be one half of the inter-fiber dlstance.

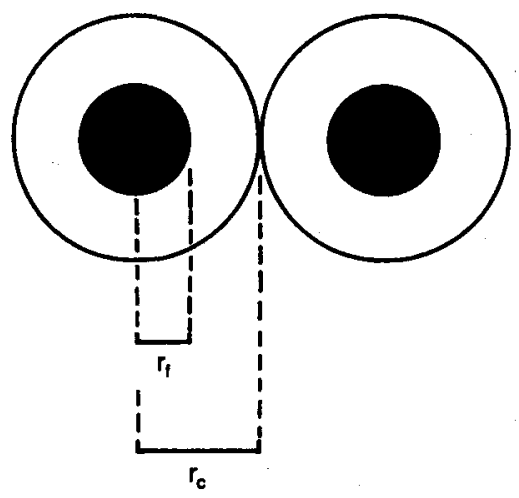

\section{The Fluid Velocity}

The differential equation for the momentum balance of viscous flow in a cylindrical annulus can be written:

$$
\frac{d}{d r}\left(r \eta_{r 2}\right)=\frac{\Delta P}{4} r
$$

where $r$ is the distance from the center of the fiber to any point between the fiber and the surrounding cylinder. The factor $\eta_{r z}$ represents the shear stress on the flowing fluid in the $z$ direction (direction of flow) along the radial distance. This can be written:

$$
\eta_{r 2}=-\mu \frac{d V_{z}}{d r}
$$

where $\mu$ is the viscosity of the fluid, and $V_{2}$ is its velocity through the annulus. 
Integration of equation 1A:

$$
\int \frac{d}{d r}\left(r \eta_{r 2}\right)=\frac{\Delta P}{L} \int r d r
$$

gives:

$$
r \eta_{r z}=\frac{\Delta P}{2 L_{i}} r^{2}+1
$$

or:

$$
\eta_{r z}=\frac{\Delta P}{2 L} r+\frac{1}{r}
$$

where $I$ is an integration constant. This constant can be evaluated from the boundary condition that the velocity is the greatest when $r$ is equal to the radius of the outer cylinder, $r_{c}$, that is $\mathrm{dV}_{z} / \mathrm{dr}=0$ and therefore $\eta_{\mathrm{z}}=0$. Under this condition:

$$
I=-\frac{\Delta P}{2 L} r_{c}^{2}
$$

Substituting this expression into equation $5 \mathrm{~A}$ gives:

$$
\eta_{r z}=\frac{\Delta P}{2 L_{i}}\left(\frac{r^{2}-r_{c}^{2}}{r}\right)
$$

Using equation $2 A$, this becomes

$$
\frac{d V_{2}}{d r}=-\frac{\Delta P}{2 \mu L_{4}}\left(\frac{r^{2}-r_{c}^{2}}{r}\right)
$$

and integrating:

$$
\int d V_{z}=-\frac{\Delta P}{2 \mu L_{t}} \int\left(\frac{r^{2}-r_{c}^{2}}{r}\right) d r
$$

gives:

$$
V_{z}=-\frac{\Delta P}{2 \mu L_{t}}\left(\frac{r^{2}}{2}-r_{c}^{2} \ln r+1\right)
$$

This integration constant, $l$, can be evaluated from the boundary condition that the fluid flow is viscous, i.e. at the surface of the fiber, $r_{f}$ the fluid velocity is zero. Under this condition:

$$
I=-r_{f}^{2} / 2+r_{c}^{2} \ln r_{f}
$$

Substituting this expression into equation $10 \mathrm{~A}$ yields:

$$
V_{2}=\frac{\Delta P}{2 \mu L}\left[\left(\frac{r_{1}^{2}-r^{2}}{2}\right)+r_{c}^{2} \ln \left(\frac{r}{r_{i}}\right)\right]
$$

or:

$$
V_{z}=\frac{\Delta P}{2 \mu L_{i}}\left(\frac{r_{f}^{2}}{2}-r_{c}^{2} \ln r_{f}-\frac{r^{2}}{2}+r_{c}^{2} \ln r\right)
$$


III. The Average Fluid Velocity

The average fluid velocity can be found through:

$$
\left\langle v_{z}\right\rangle=\int_{0}^{2 \pi} \int_{r_{f}}^{r_{c}} v_{z} r d r d \theta / \int_{0}^{2 \pi} \int_{r_{f}}^{r_{c}} r d r d \theta
$$

Because of the cylindrical symmetry of this model, $V_{2}$ is independent of the cylindrical coordinate $\Theta$, and equation 13A may be rewriteten:

$$
\left\langle v_{z}\right\rangle=\int_{r_{f}}^{r_{c}} v_{z} r d r / \int_{r_{f}}^{r_{c}} r d r
$$

The integral in the denominator is equal to:

$$
\int_{r_{t}}^{r_{c}} r d r=\frac{r_{c}^{2}-r_{f}^{2}}{2}
$$

The remaining integral can be written as:

$$
\int_{r_{1}}^{r_{c}} V_{z} r d r=\frac{\Delta P}{2 \mu L_{i}}\left(\frac{r_{f}^{2}}{2}-r_{c}^{2} \ln r_{f}\right) \int_{r_{f}}^{r_{c}} r d r-\frac{\Delta P}{4 \mu L_{f}} \int_{r_{f}}^{r_{c}} r^{3} d r+\frac{\Delta P r_{c}^{2}}{2 \mu L_{i}} \int_{r_{f}}^{r_{c}} r \ln r d r,
$$

which is equal to:

$$
\int_{r_{f}}^{r_{c}} V_{z} r d r=\frac{\Delta P}{2 \mu L_{f}}\left(\frac{r_{f}^{2}}{2}-r_{c}^{2} \ln r_{f}\right)\left(\frac{r_{c}^{2}-r_{f}^{2}}{2}\right)-\frac{\Delta P}{4 \mu \cdot L_{f}}\left(\frac{r_{c}^{4}-r_{f}^{4}}{4}\right)+\frac{\Delta P r_{c}^{2}}{2 \mu L}\left(\frac{r_{c}^{2}}{2} \ln r_{c}-\frac{r_{c}^{2}}{4}-\frac{r_{f}^{2}}{2} \ln r_{f}+\frac{r_{f}^{2}}{4}\right),
$$

which, on rearrangement, gives:

$$
\int_{r_{f}}^{r_{c}} V_{z} r d r=\frac{\Delta P r_{c}^{+}}{8 \mu L_{i}}\left[-\ln \left(\frac{r_{f}}{r_{c}}\right)^{2}+\left(\frac{r_{f}}{r_{c}}\right)^{2}-0.5\left(\frac{r_{f}}{r_{c}}\right)^{4}-1.5\right]
$$

Using the notation:

$$
\alpha=\frac{r_{f}^{2}}{r_{c}^{2}}
$$

equation 18A can be written:

$$
\int_{r_{f}}^{r_{c}} V_{z} r d r=\frac{\Delta P r_{f}^{4}}{8 \mu L_{f} \alpha^{2}}\left(-\ln \alpha+\alpha-0.5 \alpha^{2}-1.5\right)
$$

[20A]

and equation 15A becomes:

$$
\int_{r_{f}}^{r_{c}} r d r=\frac{r_{f}^{2}}{2}\left(\frac{1-\alpha}{\alpha}\right)
$$

167 
Substituting equations $20 \mathrm{~A}$ and $21 \mathrm{~A}$ into equation $14 \mathrm{~A}$ gives:

$$
\left\langle V_{z}\right\rangle=\frac{\Delta P r_{f}^{2}}{4 \mu L_{1} \alpha(1-\alpha)}\left(-\ln \alpha+\alpha-0.5 \alpha^{2}-1.5\right)
$$

IV. The Volumetric Flow Rate

The volumetric flow rate can be found from:

$$
Q=\pi\left(r_{c}^{2}-r_{f}^{2}\right)\left\langle v_{z}\right\rangle
$$

Comparing this expression with equations $14 A$ and $15 A$ gives:

$$
Q=2 \pi \int_{r_{f}}^{r_{c}} v_{z} r d r
$$

Therefore, the flow rate can be found directly from equation 20A:

$$
Q=\frac{\pi \Delta P r_{f}^{4}}{4 \mu L_{1} \alpha^{2}}\left(-\ln \alpha+\alpha-0.5 \alpha^{2}-1.5\right)
$$

\section{The Langmuir Pressure-Drop Equation}

Rearranging equation 25A gives:

$$
\Delta P=\frac{4 \mu L_{f} \alpha^{2} Q \Phi}{\pi r_{f}^{4}}
$$

where $\Phi$, the hydrodynamic factor, is:

$$
\Phi=\left(-\ln \alpha+\alpha-0.5 \alpha^{2}-1.5\right)^{-1}
$$

Equation 26A represents the pressure drop across a single cylinder. For a collection of $n_{f}$ cylinders in parallel:

$$
\Delta P_{t}=\Delta P / n_{t}
$$

Substituting equation $26 \mathrm{~A}$ into this expression yields

$$
\Delta P_{t}=\frac{4 \mu L_{i} \alpha^{2} Q \Phi}{\pi n_{f} r_{f}^{4}}
$$

or, using equation 19A:

$$
\Delta P_{t}=\frac{4 \mu L_{1} \alpha Q \Phi}{n_{f} \pi r_{c}^{2} r_{f}^{2}}
$$

The total cross-sectional area of the filter is equal to $n_{f} \pi r_{c}^{2}$, thus equation 30A may be written:

$$
\Delta P_{t}=\frac{4 \pi \mu L_{1} \alpha Q \Phi}{A_{F} A_{t}}
$$

This is the LANGMUIR pressure drop equation. 